\title{
A APRENDIZAGEM TEORICO-VIVENCIAL: EXPLORAÇÃO DE ALGUNS LIMITES E POSSIBILIDADES
}

\author{
Marisa Japur ( $\left.{ }^{*}\right)$ \\ Sonia Regina Loureiro (**) \\ Maria Auxiliadora Campos (**) \\ Denise Bouttelet Munari (***)
}

\section{RESUMO}

Esse estudo foi delineado com o objetivo de comparar a disponibilidade inicial de um grupo de alunos para uma proposta de aprendizagem teórico-vivencial com mudanças auto-observadas no final do processo. $\mathrm{O}$ grupo foi constituído por 12 alunos inscritos na disciplina "Dinâmica do Relacionamento Humano", oferecida em um Programa de Pós-Graduação para profissionais da Área de Saúde Mental. Os dados foram obtidos através de respostas dos participantes a questões abertas feitas no início e no final do processo do grupo, e fram tratadas pelo procedimento de análise categorial de conteúdo. Os resultados evidenciaram que a falta de disponibilidade inicial para a tarefa grupal não se constituiu em fator impeditivo de mudanças positivas posteriores, enquanto que a disponibilidade associada a necessidades pessoais de interação, constituiu-se em limite para o alcance desse tipo de proposta.

\section{INTRODUÇÃO}

No contexto desse trabalho, a expressão aprendizagem teórico-vivencial é utilizada para referir um processo de aprendizagem em que a experiência do aluno é tomada como objeto de reflexão, enquanto significante dos conteúdos teóricos propostos como temas para a aprendizagem. Esse modelo de aprendizagem tem como pressuposto que as mudanças que ocorrem como conseqüência da aprendizagem implicam uma modificaçāo na forma de perceber a si mesmo e à realidade externa, envolvendo tanto aspectos intelectuais como afetivos.

MORENO (1983) define esse processo como aprendizagem signifi-

\footnotetext{
() Prop Dr" do Departamento de Psicologia e Educaçăo, FFCLRP-USP.

*.* Prof Dr* do Departamento de Psiquiatria e Psicologia Médica, FMRP-USP.

**) Prof Assistente do Departamento de Enfermagem Psiquiátrica e Ciéncias Humanas, EERP-USP.
}

Paidéia, FFCLRP - USP, Rib. Preto, 2, Fev/Jul, 1992. 
cativa, "como uma assimilação a mim mesmo daquilo que aprendo, em contraposição a uma mera assimilação de conhecimentos e informaçōes sem nenhuma conexão comigo".

Muitos professores têm valorizado esse processo de aprendizagem por reconhecerem a importância do desenvolvimento pessoal do aluno, sobretudo na formação daqueles profissionais que têm a própria interação humana, seja interpessoal ou grupal, como o recurso essencial à sua atuação profissional.

Apesar disso, poucas vezes, a aprendizagem teórico-vivencial tem sido um objetivo explícito dos programas acadêmicos de formação desses profissionais. De um modo geral, a formação profissional do aluno na universidade tem sido planejada em termos intelectuais. Valoriza-se a aquisição de conhecimentos, privilegiando a formação de uma base científica e técnica. Como aponta DOXEY (1986), "seria uma farsa presumir que o desenvolvimento da potencialidade humana do aluno fosse uma meta, ainda que implícita, da Universidade Brasileira".

Isso faz com que as disciplinas que trazem essa proposta de aprendizagem se configurem como experiências isoladas no contexto da história acadêmica dos alunos. Em nossa experiência docente, quando a aprendizagem teorico-vivencial $e$ um objetivo explicitamente colocado, desperta diferentes expectativas nos alunos e diferentes maneiras de valorizá-la, dificultando uma apreensão mais imediata de seus limites e possibitidades.

Foi com a intenção de compreender melhor algumas dimensōes desse modelo de aprendizagem, que elegemos a experiência com uma disciplina, proposta como teórico-vivencial, como objeto de estudo, utilizando três fontes de dados: registro sistemático de observação feito pelos coordenadores do grupo ao longo do processo, produção gráfica coletiva realizada pelos participantes no início e no final do processo e relato verbal individual, também obtido dos participantes no início e no final do processo.

Em comunicações anteriores (CAMPOS, MUNARI, LOUREIRO e JAPUR, 1990; e LOUREIRO, JAPUR, CAMPOS e MUNARI, 1990) relatamos a compreensão que obtivemos desse processo, a partir das duas primeiras fontes de dados citadas.

O presente estudo, baseado no relato verbal dos participantes, teve por objetivo comparar a disponibilidade inicial de um grupo de alunos para uma proposta teórico-vivencial com mudanças auto-observadas no final do processo. 


\section{SUJEITOS E PROCEDIMENTOS}

O grupo foi constituído por 12 alunos, predominantemente do sexo feminino, inscritos na disciplina "Dinâmica do Relacionamento Humano", oferecida em um Programa de Pós-Graduação para profissionais da área de Saúde Mental.

Essa disciplina pareceu-nos propícia à proposta de aprendizagem teórico-vivencial, uma vez que nela o objeto de estudo se presentifica concretamente no grupo e pode ser tomado para reflexāo, favorecendo uma compreensão vivenciada dos processos de interação humana.

Os dados foram obtidos sob a forma de respostas abertas a questionários aplicados coletivamente na primeira e na última aula do curso.

O primeiro questionário visou um levantamento de informações a respeito da maneira como o participante se percebia frente a proposta de uma tarefa teórico-vivencial em grupo, e foi constituído de 5 questões, dentre as quais selecionamos para esse trabalho a seguinte: "Comente sobre sua disponibilidade para participar de um grupo. que se propõe a uma aprendizagem teórico-vivencial".

O segundo questionário visou obter informaçōes sobre a maneira pela qual o participante avaliava sua participação no trabalho grupal, e foi constituído de 8 questōes, dentre as quais selecionamos para o presente trabalho a seguinte: "Durante o processo desse grupo você observou mudanças quanto ao seu modo de interagir no grupo? E quanto ao seu modo de interagir como profissional? Comente".

As respostas a essas questões foram tratadas pelo procedimento de análise categorial de conteúdo (BARDIN, 1988), que consiste em isolar as unidades de sentido que emergem dos textos analisados e reagrupá-las de forma a tornar explícitos os significados dos mesmos. Em seguida, as respostas foram classificadas no sistema de categorias obtido, permitindo caracterizá-las em seu conjunto.

\section{RESULTADOS}

As categorias derivadas da análise das respostas à questão sobre disponibilidade inicial para a tarefa teórico-vivencial são apresentadas no Quadro 1. 
Quadro 1 - Categorias relativas a disponibilidade inicial para a proposta de aprendizagem teorico-vivencial.

\begin{tabular}{|l|l|}
\hline A. A resposta sugere que o participante näo leva em conta o processo grupal: \\
\hline a.1. referindo-se à disponibilidade de & "A disponibilidade é total." \\
forma impessoal. & $\begin{array}{l}\text { tenho outras atividades além da PG, } \\
\text { mos dependendo do dio, local o duro- } \\
\text { cöo, pode-se arranjar." }\end{array}$ \\
\hline
\end{tabular}

B. A resposta sugere que o participante leva em conta o processo grupal:

\begin{tabular}{|c|c|c|}
\hline b. 1. & $\begin{array}{l}\text { apontando sua disponibilidade para } \\
\text { a tarefa grupal. }\end{array}$ & $\begin{array}{l}\text { "Estou à vontade para iniciarmos este } \\
\text { trabalho." }\end{array}$ \\
\hline b. 2 . & $\begin{array}{l}\text { relacionando sua disponibilidade } \\
\text { aos seus limites pessoais para ata } \\
\text { refa grupal. }\end{array}$ & $\begin{array}{l}\text { "A participacão em um grupo formal não } \\
\text { é fäcil. Tenho disponibilidade com al } \\
\text { gumas reservas." }\end{array}$ \\
\hline b. 3. & $\begin{array}{l}\text { relacionando sua disponibilidade } \\
\text { a novidade da tarefa. }\end{array}$ & $\begin{array}{l}\text { "Pessoalmente estou disponivel para } \\
\text { participar e vivenciar esta experiên- } \\
\text { cia que para mim è nova. Espero estar } \\
\text { aberta para receber todas as propos- } \\
\text { tas de trabalho." }\end{array}$ \\
\hline b. 4. & $\begin{array}{l}\text { relacionando sua disponibilidade } \\
\text { as suas necessidades pessoais de } 1 \text { n } \\
\text { teracäo. }\end{array}$ & $\begin{array}{l}\text { "Pelo menos a nivel consciente é gran } \\
\text { de. Talvez por estar morando em local } \\
\text { onde o espaco para discutir com ou- } \\
\text { tras pessoas as vivências e relaciona } \\
\text { mentos é muito pequeno, e entäo, estê } \\
\text { jà necessitando esse tipo de ativida } \\
\text { de." }\end{array}$ \\
\hline
\end{tabular}

Essas categorias nos permitiram, então, verificar que essa questāo, solicitando que o participante, no contexto coletivo da presença concreta de outras pessoas, se voltasse para si mesmo numa busca silenciosa dos significados pessoais relativos ao estar em grupo, favoreceu informaçőes sobre como o participante se colocou frente ao grupo, se reconhecendo ou não que a tarefa proposta implicava no acontecimento de um processo grupal, no qual ele estava sendo solicitado como sujeito do próprio processo.

Nos Quadros 2 e 3 apresentamos as categorias derivadas da análise das respostas relativas às mudanças auto-observadas no final do processo. 
Quadro 2 - Categorias relativas às mudanças auto-observadas quanto ao modo de interagir no grupo.

A. A resposta sinaliza um movimento de aproximação do grupo com o reconhecimento de mudanças no sentido de:

\begin{tabular}{l|l} 
a.1. aumento da auto-expressividade & "Sim. Percebo que entro sempre me pro
\end{tabular} tegendo muito, medrosa e foi possível ir diminuindo $o$ medo $e$ me soltando mais nas interações."

a.2. maior receptividade ao outro

"Discriminando menos as pessoas basea da em inferências minhas. Ver as pessoas como elas se expõem e não como eu quero vè-1as."

a.3. ampliação e melhora das interaçōes

"Sim. Conseguindo interagir com um nú mero maior de pessoas, com maior troca."

B. A resposta sinaliza o reconhecimento "Sim e para melhor." de mudanças positivas, mas não as es pecifica.

C. A resposta sinaliza o reconhecimento de mudanças no sentido de um movimen to de retraimento frente ao grupo.

"Não muito significativa, acho que pas sei a ponderar mais o que iria colocar no grupo." 
Quadro 3 - Categorias relativas às mudanças auto-observadas quanto ao modo de interagir como profissional.

\begin{tabular}{|c|c|}
\hline $\begin{array}{l}\text { a.1. no sentido de maior receptividade } \\
\text { ao outro nas interaçóes. }\end{array}$ & $\begin{array}{l}\text { "Estou tentando (e até certo ponto tem } \\
\text { dado certo) aceitar mais o outro como } \\
\text { ele é não como eu gostaria que ele } \\
\text { fosse." }\end{array}$ \\
\hline a.2. no modo de pensar as interações. & $\begin{array}{l}\text { "Avancei na anälise das questões refe } \\
\text { rentes a interaçóes interpessoais." }\end{array}$ \\
\hline $\begin{array}{l}\text { a.3. no sentido de maior auto-confiança } \\
\text { nas interaçóes. }\end{array}$ & $\begin{array}{l}\text { "0 curso foi concomitante com o } 19 \text { se } \\
\text { mestre que assumi a docencia de forma } \\
\text { mais efetiva. Considero que a judou-me } \\
\text { a sentir mais a vontade econfiante no } \\
\text { grupo dos alunos." }\end{array}$ \\
\hline a.4. como possibilidade futura. & $\begin{array}{l}\text { "Procurei transpor para fora as várias } \\
\text { situaçóes vividas no grupo e a partir } \\
\text { dos conceitos teóricos de desenvolvi- } \\
\text { mento de grupos, acho que vai ser pos } \\
\text { sível uma transformaça para melhor." }\end{array}$ \\
\hline \multicolumn{2}{|c|}{ B. A resposta não aponta mudanças no modo de interagir como profissional: } \\
\hline $\begin{array}{l}\text { b.1. por não estar exercendo nenhum pa- } \\
\text { pel profissional. }\end{array}$ & $\begin{array}{l}\text { "No momento estou me dedicando exclu- } \\
\text { sivamente a PG, mas a minha percepcão } \\
\text { enquanto membro de um grupo sofreu al } \\
\text { teraçoses." }\end{array}$ \\
\hline b.2. por não reconhecê-1as. & $\begin{array}{l}\text { "Não, ainda, isto é, pelo que eu pos- } \\
\text { so avaliar." }\end{array}$ \\
\hline
\end{tabular}

A análise dessas respostas permitiu verificar que as mudanças auto-observadas tanto no modo de interagir no grupo como no modo de interagir como profissional, foram de natureza bastante diferentes entre si, apontando para a diversidade possível de repercussão que a proposta de aprendizagem teórico-vivencial pode vir a ter nos participantes.

Na Tabela 1 apresentamos a distribuição cruzada das respostas dos 12 participantes nas categorias relativas à disponibilidade para tarefa proposta e às mudanças auto-observadas no final do processo. 


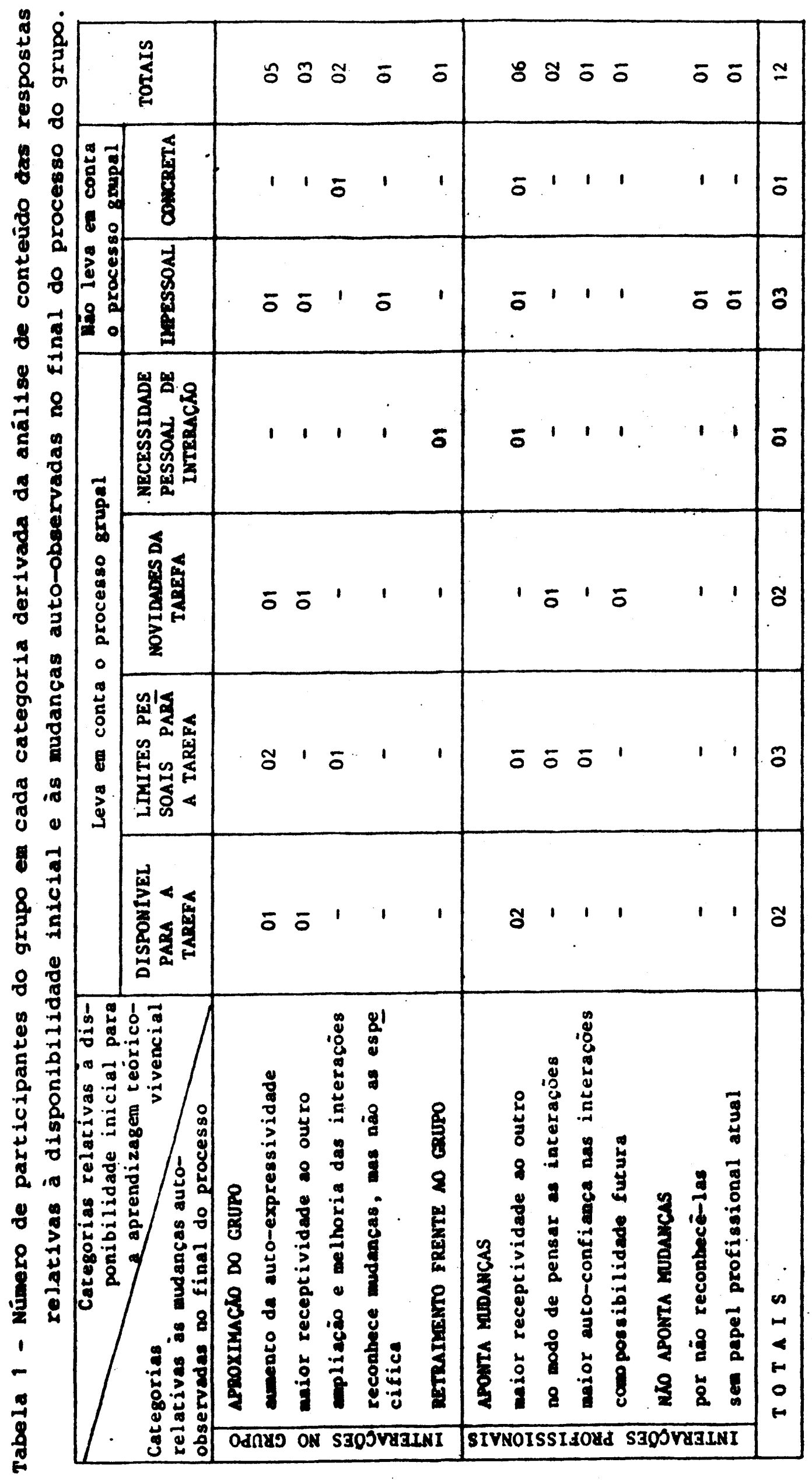


Nessa tabela verificamos que 8 dos 12 participantes (67\%) apresentaram indícios de que iniciaram o trabalho levando em conta a ocorrência de um processo grupal, parecendo reconhecerem-se como sujeitos desse próprio processo. Dentre eles, 2 manifestaram sua disponibilidade para a tarefa; 3 deles a relacionaram aos seus limites pessoais para a tarefa proposta; outros 2 a relacionaram à novidade da mesma; e finalmente um deles manifestou sua disponibilidade associando-a às suas necessidades pessoais de interação.

Os outros 4 participantes (33\%) apresentaram indícios de que ao iniciarem o trabalho não tinham presente a ocorrência de um processo grupal que os requeria como sujeitos do mesmo. Dentre esses participantes, 3 referiram-se à disponibilidade de maneira impessoal e o outro, ao sentido concreto da mesma.

Também na Tabela 1 é possível verificar que a totalidade dos participantes reconheceu mudanças em sua forma de interagir no grupo ao longo do processo. Dos 12 participantes, 10 deles $(83 \%)$ relataram mudanças em direções que sugerem maior aproximação do grupo. Dentre eles, 5 assinalaram o aumento da auto-expressividade; 3 deles, uma maior receptividade ao outro e os outros 2, ampliação e melhoria na qualidade das interaçōes. Dos outros 2 participantes (17\%) um deles reconheceu mudanças no seu modo de interagir no grupo e apesar de não especificá-las, tendeu a valorizá-las positivamente; e o outro participante assinalou mudanças que sugerem um movimento de retraimento frente ao grupo.

Além disso, também 10 dos 12 participantes (83\%) assinalaram mudanças nas suas interações profissionais, tendo predominado 0 reconhecimento de maior receptividade ao outro nas interações (6 participantes). Dois participantes assinalaram mudanças no seu modo de pensar as interaçōes; 1 outro assinalou reconhecer-se mais auto-confiante em situações grupais; e o outro apontou a possibilidade futura de mudanças no seu modo de interagir como profissional.

Finalmente, apenas um dos participantes do grupo $(8,3 \%)$ não reconheceu mudanças em suas interações profissionais; e o outro assinalou que não estava exercendo, no momento, nenhum papel profissional.

A comparação das respostas iniciais sobre a disponibilidade para a tarefa e as mudanças auto-observadas no modo de interagir no grupo permitiu verificar que mesmo aqueles participantes que inicialmente não pareciam levar em conta o processo grupal, tornaram-se permeáveis a ele ao longo do trabalho, possibilitando o reconhecimento de mudanças positivas em suas interações grupais. Essas mesmas mudanças foram tambem relatadas pelos participantes que inicialmente levavam em conta a sua inserção em um processo grupal, com exceção daquele que associou sua disponibilidade à satisfação de suas necessidades pessoais de interação.

Paidéia, FFCLRP - USP, Rib. Preto, 2, Fev/Jul, 1992. 
Por outro lado, todos os participantes que se mostraram inicialmente disponíveis para tarefa grupal, relataram mudanças no seu modo de agir como profissional; e apenas um dos participantes que se referiu inicialmente à disponibilidade de maneira impessoal, não apontou o reconhecimento de mudanças em suas interaçōes profissionais, ao final do processo grupal.

\section{CONCLUSÃo}

A verificação de que apenas o participante que associou sua disponibilidade para a tarefa teórico-vivencial proposta às suas necessidades pessoais de interação, reconheceu-se no final do processo em movimento de retraimento frente ao grupo, vai de encontro à nossa observação, fruto de nossa experiência docente, de que os participantes que depositam neste tipo de grupo expectativas que seriam mais adequadas a grupos com propósitos explicitamente terapêuticos, tendem a se frustrar com o processo.

Na nossa avaliação, esse parece constituir-se em um limite a ser considerado nas propostas teórico-vivencionais, uma vez que sua proposição em contextos acadêmicos nem sempre permite processos prévios de seleção dos participantes do grupo.

Por outro lado, a constatação de que aqueles participantes que inicialmente não demonstraram reconhecerem-se como sujeitos de um processo grupal, e mesmo aqueles que se reconheceram com limites pessoais para a tarefa proposta, apontaram no final do processo mudanças positivas em suas interações, evidencia uma possibilidade dessa proposta, como um processo potencialmente capaz de fomentar o desenvolvimento pessoal, tão desejável na formação de profissionais que têm a interação humana como instrumento essencial de seu trabalho.

Além disso, a verificação de que a grande maioria dos participantes do grupo relatou mudanças em seu modo de interagir como profissionais, aponta também para a possibilidade da aprendizagem realizada no contexto do grupo ser generalizada para a situação profissional. Ao nosso ver, essa verificação tende a legitimar a inserção de propostas teórico-vivenciais no contexto da formação acadêmica desses profissionais.

Finalmente, consideramos que dentro do contexto da metodologia desse trabalho, foi-nos possível suscitar alguns questionamentos sobre limites e alcance da proposta de aprendizagem teórico-vivencial, que esperamos possa encorajar o desdobramento de estudos sobre a mesma. 


\section{REFERÊNCIAS}

BARDIN, L. Análise de conteúdo. Lisboa, Ediçōes 70, 1988.

CAMPOS, M. A.; MUNARI; D. B.; LOUREIRO, S. R. e JAPUR, M. Dinâmica de Grupo: Reflexões sobre um curso teórico-vivencial. Ribeirão Preto: Anais do II Encontro de Pesquisadores em Saúde Mental e II Encontro de Enfermeiros Psiquiátricos, 1990. p. 102-123.

DOXEY, J. R. A sala de aula universitária como comunidade de aprendizagem e contexto psicossociológico para mudança. In: CAPPELLETTI, F. I. e MASETTO, M. T. Ensino superior: reflexões e experiências. São Paulo, EDUC, 1986. p. 147-200.

LOUREIRO, S. R.; JAPUR, M.; CAMPOS, M. A. e MUNARI, D. B. A produção gráfica coletiva de um grupo de alunos como elemento projetivo de expectativas e da avaliação do processo grupal. Ribeirão Preto: Anais do II Encontro de Pesquisadores em Sá́de Mental e II Encontro de Enfermeiros Psiquiátricos, 1990. p. 124-141.

MORENO, S. La educacion centrada en la persona. México, Ed. El Manual Moderno S.A., $2^{2}$ ed., 1983.

\section{ABSTRACT}

The present study was designed with the objective of comparing the initial availability of a group of students for a proposal of theoretical-living learning with self-observed changes at the end of the process. The gourp consisted of 12 students enrolled in the discipline "Dynamics of Human Relations" wich is offered in a Post-Graduate Program for professionals in the Mental Health Area. The data were obtained from the responses of the participants to open questions asked at the beginning and at the end of the group process and were analyzed by content category analysis. The results showed that the lack of initial availability for the group task did not represent a factor preventing later positive changes, whereas availability associated with personal needs for interaction represented a limit for the reach of this type of proposal. 